\title{
Bilateral Molecular Changes in a Neonatal Rat Model of Unilateral Hypoxic-Ischemic Brain Damage
}

\author{
EVELYN R.W. VAN DEN TWEEL, ANNEMIEKE KAVELAARS, MARIA STELLA LOMBARDI, CORA H.A. NIJBOER, \\ FLORIS GROENENDAAL, FRANK VAN BEL, AND COBI J. HEIJNEN
}

\author{
Department of Neonatology [E.R.W.T., C.H.A.N., F.G., F.B.], Laboratory for Psychoneuroimmunology and Perinatology [E.R.W.T., A.K., \\ M.S.L., C.H.A.N., C.J.H.], University Medical Center Utrecht, 3584 EA Utrecht, The Netherlands
}

\begin{abstract}
Perinatal hypoxia ischemia (HI) is a frequent cause of neonatal brain injury. This study aimed at describing molecular changes during the first $48 \mathrm{~h}$ after exposure of the neonatal rat brain to HI. Twelve-day-old rats were subjected to unilateral carotid artery occlusion and $90 \mathrm{~min}$ of $8 \% \mathrm{O}_{2}$, leading to neuronal damage in the ipsilateral hemisphere only. Phosphorylated-Akt levels were decreased from 0.5 to $6 \mathrm{~h}$ post-HI, whereas the level of phosphorylated extracellular signal-related kinases (ERK) $1 / 2$ increased during this time frame. Hypoxia-inducible factor (HIF)- $1 \alpha$ protein increased with a peak at $3 \mathrm{~h}$ after HI. mRNA expression for IL- $\beta$ and tumor necrosis factor- $\alpha$ and $-\beta$ started to increase at $6 \mathrm{~h}$ with a peak at $24 \mathrm{~h}$ post-HI. Expression of heat shock protein 70 was increased from $12 \mathrm{~h}$ after HI onwards in the ipsilateral hemisphere only. Surprisingly, HI changed the expression of cytokines, HIF1- $\alpha$, and P-Akt to the same extent in both the ipsi- as well as the contralateral hemisphere, although neuronal damage was unilateral. Exposure of animals to hypoxia without carotid artery occlusion induced similar changes in cytokines, HIF- $1 \alpha$, and P-Akt. We conclude that during HI, hypoxia is sufficient to regulate multiple molecular mediators that may contribute, but are not sufficient, to induce long-term neuronal damage.

(Pediatr Res 59: 434-439, 2006)
\end{abstract}

$\mathrm{P}_{\mathrm{o}}$ erinatal $\mathrm{HI}$ followed by reperfusion is an important cause of neonatal brain injury (1-3). The underlying mechanisms leading to neuronal cell death are numerous and complex.

A commonly used neonatal rat model to investigate hypoxic-ischemic brain damage is the Vannucci-Rice model. This model implicates unilateral common carotid artery ligation followed by inhalation of $8 \% \mathrm{O}_{2}$ for $1-2 \mathrm{~h}$. This procedure leads to cerebral damage restricted to the hemisphere ipsilateral to the occluded artery (4).

Early after induction of cerebral damage, death, and survival, kinase signalling pathways are known to be activated, including the phosphatidyl-inositol 3 kinase/Akt (PI3-K/Akt) and the ERK1/2 pathways. The phosphorylated forms of these kinases have been shown to be up-regulated after $\mathrm{HI}$ in vivo as well as in vitro and are thought to be involved in neuronal cell apoptosis (5-7). Activation of the PI3-K/Akt and the ERK1/2 signaling routes enhance translation of the transcription factor

Received May 25, 2005; accepted November 1, 2005.

Correspondence: Cobi J. Heijnen, Ph.D., Laboratory for Psychoneuroimmunology and Perinatology, University Medical Center Utrecht, Room KC 03.063.0, P.O. Box 85090, 3508 AB Utrecht, The Netherlands; e-mail: c.heijnen@azu.nl
HIF-1 $\alpha$ (8-10). In addition, reduced cellular oxygen levels increase the stability of HIF- $1 \alpha$ protein. More than 40 genes containing the promoter sequence for HIF- $1 \alpha$ have been identified. Most of these genes play a key role in neuroprotective processes such as angiogenesis/vascular remodeling, erythropoiesis, glucose transport, glycolysis, iron transport, and cell proliferation/neuronal survival (11). Increased HIF-1 $\alpha$ levels therefore regulate adaptation of the cell to a hypoxic environment (12). Another factor induced after HI that has been implicated in both cellular protection and damage, is HSP70. HSP70 is a chaperone molecule, which is induced in cells after stress such as heat, stretch, or hypoxia $(13,14)$. Intracellular HSP70 is thought to protect cells by binding to denatured proteins, thereby preventing further denaturation or degradation of the proteins. In addition, there is evidence that extracellular HSP70 can activate pathways leading to cell death $(15,16)$.

Several studies suggest that the cytokine response in the brain after $\mathrm{HI}$ is an important factor in contributing to neuronal cell death. In P7 rats, $\mathrm{HI}$ induces an increase in proinflammatory cytokines such as IL- $1 \beta$, TNF- $\alpha$, and of chemokines like macrophage inflammatory protein (MIP)- $1 \alpha$ in the ipsilateral hemisphere (17).

The aim of the present study was to carefully define early changes in molecular mediators after neonatal $\mathrm{HI}$ in the ipsiand contralateral hemisphere to facilitate identification of the factors that are crucial for inducing cerebral damage and thus could be targets for therapy. We choose the model of P12 rats because the developmental stage of the brain of a P12 rat is comparable to the stage of development of the brain of a full-term human neonate $(18,19)$. We analyzed the kinetics of the changes in expression of HIF- $1 \alpha$, P-Akt, P-ERK1/2, HSP70, and of cytokines in P12 rats over a period from $30 \mathrm{~min}$ to $48 \mathrm{~h}$ after $\mathrm{HI}$.

\section{MATERIALS AND METHODS}

Animal protocol. The experimental animal committee (UMC Utrecht) approved all animal protocols. Twelve-day-old Wistar rats were used as a model of full-term human neonates $(19,20)$. A total of 109 animals was

Abbreviations: ERK, extracellular signal-related kinases; HI, hypoxia-ischemia HIF-1 $\alpha$, hypoxia-inducible factor- $1 \alpha$; HSP70, heat shock protein 70 ; TNF, tumor necrosis factor 
subjected to HI: The right common carotid artery was ligated under halothane anaesthesia (5.0\% induction, $2.0 \%$ maintenance) followed by $60 \mathrm{~min}$ recovery and $90 \mathrm{~min} 8 \% \mathrm{O}_{2} / 92 \% \mathrm{~N}_{2}$. Pups were killed by decapitation and left and right hemispheres were stored at $-80^{\circ} \mathrm{C}$. Thirty-three sham-operated control animals underwent anesthesia and incision without artery occlusion and without hypoxia. To assess the effect of hypoxia without carotid artery occlusion, 10 additional sham-operated animals were exposed to $90 \mathrm{~min}$ of hypoxia $\left(8 \% \mathrm{O}_{2} /\right.$ $92 \% \mathrm{~N}_{2}, 37^{\circ} \mathrm{C}$ ).

Histology. Six weeks after HI, pups were sedated with pentobarbital, perfused with $4 \%$ paraformaldehyde in PBS, and brains were embedded in paraffin. Coronal sections of $8 \mu \mathrm{m}$ were stained with hematoxylin/eosin. Full section images were captured with a Nikon D1 digital camera (Tokyo, Japan) and processed in Adobe Photoshop 5.0 (Adobe Systems, Mountain View, $\mathrm{CA})$. The area of the ipsi- and contralateral hemisphere was measured. Damage was scored in CA1, CA2, CA3, and CA4 of the hippocampus, in the dentate gyrus, and in sic areas of the parietal cortex on a four-point scale: 3 $=$ normal; $2=$ few neurons damaged or lost; $1=$ moderate number of neurons damaged/lost; $0=$ almost all neurons lost and cystic infarction. For an example, see Figure 1. The maximum cumulative score was 33 points.

Immunohistochemistry. For immunohistochemical analyses of early changes in microtubule-associated protein (MAP)2, HSP70, and CD68, animals were transcardially perfused at $6,12,24$, or $48 \mathrm{~h}$ after $\mathrm{HI}$ and tissue was processed as described above. Immunohistochemistry was performed with mouse-anti-HSP70 (Stressgen Biotech, Victoria, Canada), mouse-anti-MAP2 (Sigma Chemical Co.-Aldrich, Steinheim, Germany), or mouse-anti-CD68FITC (Serotec, Raleigh, NC). Sections were then incubated with horse-antimouse-biotin (Vector Laboratories, Burlingame, CA) or rat-anti-FITC-biotin (Roche, Basel, Switzerland). Visualization was performed using a Vectastain $\mathrm{ABC}$ kit (Vector Laboratories). Sections were counterstained with hematoxylin.

Sections stained for MAP2 were scored in the hippocampus and in the cortex. MAP2 score: $0=$ all neurons positive, $1=$ scattered single negative cells, $2=$ a small cluster of negative cells, $3=$ many negative cells; $4=$

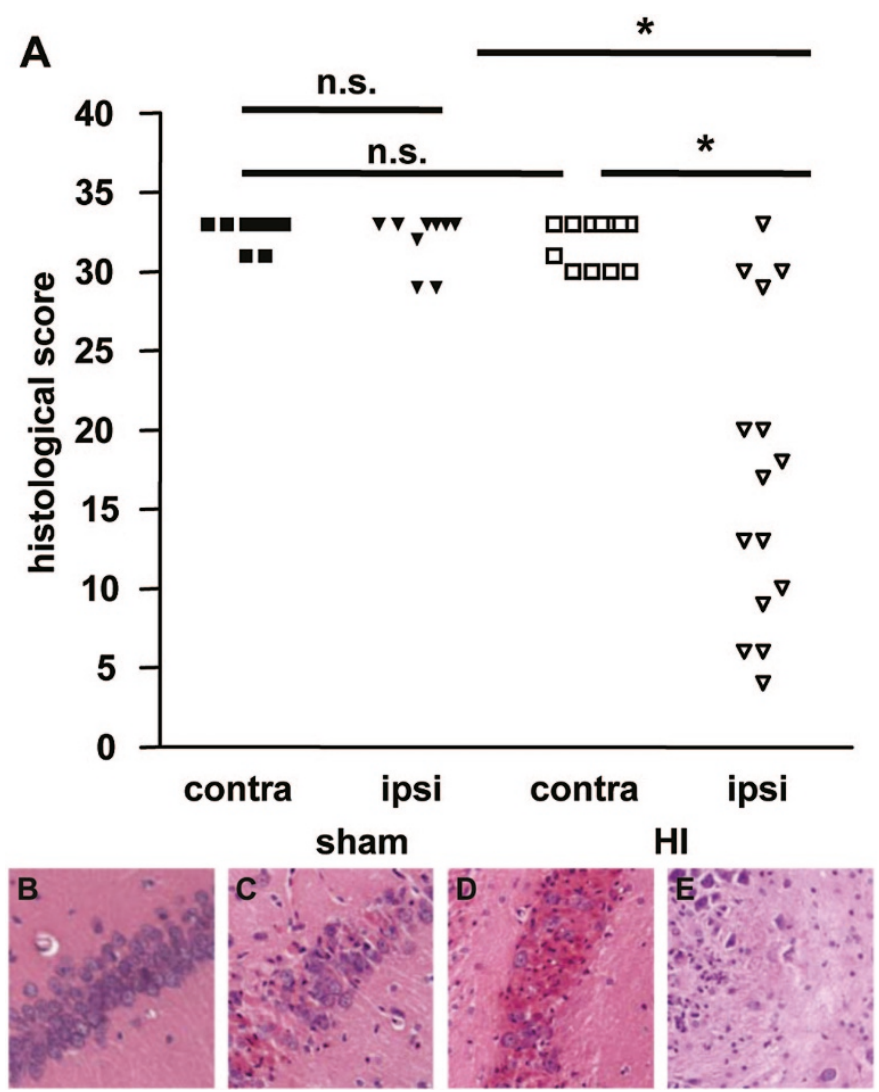

Figure 1. A histologic analysis of brain damage $6 \mathrm{wk}$ after sham-operation $(n$ $=11)$ or $\mathrm{HI}(n=14)$. Cerebral damage was scored in six areas of the cortex, the CA1, CA2, CA3, and CA4 of the hippocampus and dentate gyrus on a four-point scale (range $0-3$ ), resulting in a maximal cumulative histologic score of 33. NS, not statistically significant; $* p<0.001 . B-E$ are examples of the histologic score in the hippocampus: $B=0, C=1, D=2, E=3$. almost all cells are negative. The number of CD68- or HSP70-positive cells per high-power field was determined by counting 15 high-power fields in the hippocampus or 25 high-power fields in the cortex. Because only isolated positive cells were observed in the contralateral hemisphere and the number of positive cells at the contralateral side did not change over time, only data for the ipsilateral hemisphere are depicted.

Western blotting. Hemispheres were homogenized in $50 \mathrm{mM}$ Tris, $5 \mathrm{mM}$ EDTA, $150 \mathrm{mM} \mathrm{NaCl}$, with phosphatase and protease inhibitors. Proteins were separated by $10 \%$ SDS-PAGE and transferred to nitrocellulose membranes (Hybond-C, Amersham, Little Chalfont, Buckinghamshire, UK). Blots were stained with anti-HSP70 (Stressgen Biotech), anti-Akt (a gift from Prof. Dr. J.L. Bos, Department Physiologic Chemistry, UMC Utrecht, Utrecht, The Netherlands), anti-phospho-Akt (Ser 473, Cell Signalling Technology, Beverly, MA), anti-HIF-1 $\alpha$ (Abcam, Cambridge, Cambridgeshire, UK) or antiphospho-ERK and anti-ERK (Santa Cruz Biotechnology Inc., Santa Cruz, CA) followed by goat-anti-mouse-HRP (Sigma Chemical Co.-Aldrich), or goat-anti-rabbit-HRP (Amersham) and developed by enhanced chemiluminescence (ECL, Amersham). Band density was determined with a GS-700 densitometer (Bio-Rad, Hercules, CA).

Cytokine mRNA. Total brain RNA was extracted using Trizol. RNase protection assays were performed using the rat cytokine multi-probe template set rCK-1 (Riboquant, BD PharMingen, San Diego, CA). Autoradiographs were scanned and values were normalized using L32 expression in each sample.

For real-time PCR, cDNA was synthesized from $0.5 \mu \mathrm{g}$ total RNA with the Superscript RNase H-Reverse Transcriptase kit (Invitrogen) using random hexamers. Real-time PCR was performed using Fast Start DNA Master SYBR-green I kit and LightCycler (Roche Applied Science, Mannheim, Germany). Oligonucleotide primers (IL-1 $\beta$ Fw: 5'CACCTCTCAAGCAGAGCACAG-3'; Rev 5'GGGTTCCATGGTGAAGTCAAC-3'; 18sRNA: Fw 5'-GTAACCCGTTGAACCCCATT; Rev 5'-CCATCCAATCGGTAGTAGCG) were from TibMolbiol (Berlin, Germany). Reactions were performed with $0.5 \mu \mathrm{M}$ primers and $4 \mathrm{mM} \mathrm{MgCl}_{2}$ using 10 min denaturation at $95^{\circ} \mathrm{C}$ and 40 cycles at $95^{\circ} \mathrm{C}(10 \mathrm{~s}), 66^{\circ} \mathrm{C}(10 \mathrm{~s}), 72^{\circ} \mathrm{C}(7 \mathrm{~s})$. Melting curve analysis and agarose gel electrophoresis confirmed specificity. 18S rRNA was used for data normalization.

Statistics. Data are presented as mean and SEM. Kruskal-Wallis ANOVA was used for analyzing changes over time. Mann-Whitney $U$ test was used to further analyze differences between control and HI-treated rats at each time point. Wilcoxon signed rank test was used to compare contralateral versus ipsilateral hemispheres. A value of $p<0.05$ was considered statistically significant.

\section{RESULTS}

Brain damage. The histologic score of the ipsilateral hemisphere of rats exposed to HI was significantly $(p<0.001)$ lower than that of the contralateral hemisphere (Fig. 1). The histologic score of the contralateral hemisphere of HI rats was similar to the score sham control rats (Fig. 1). These data confirm that the HI procedure induces neuronal damage only in the hemisphere ipsilateral to the occlusion of the carotid artery.

To analyze the extent of early neuronal damage, we performed immunohistochemistry for MAP2, a marker for neuronal integrity (21). Analysis of the expression of MAP2 at 6-24 h after HI, shows a decrease of MAP2 staining in the ipsilateral hippocampus and cortex over time after HI, indicating an early loss of neuronal integrity (Fig. 2). The ipsilateral decrease of MAP2-positive cells was detectable at $6 \mathrm{~h}$ and continued to decrease until $48 \mathrm{~h}$ after HI. In the contralateral hemisphere of HI-treated rats, MAP2 staining was similar to sham control animals.

$\boldsymbol{P}$ - $\boldsymbol{A} \boldsymbol{k} \boldsymbol{t}$. The expression of P-Akt was significantly $(p<$ $0.001)$ decreased in both ipsi- and contralateral hemispheres at 0.5, 1, and $3 \mathrm{~h}$ after HI (Fig. $3 a$ ) in comparison with shamtreated rats. Subsequently, at $12 \mathrm{~h}$ post-HI, P-Akt levels returned to levels observed in sham-treated animals. However, at 24 and $48 \mathrm{~h}$ post-HI, P-Akt levels decreased again $(p<$ 

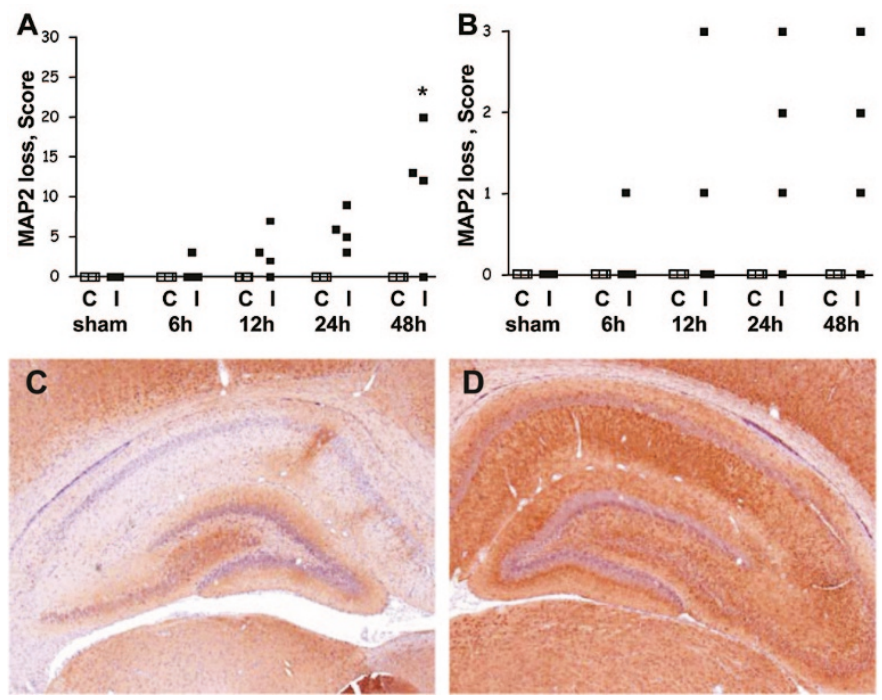

Figure 2. Immunohistochemical analysis of MAP2 expression at 6, 12, 24, and $48 \mathrm{~h}$ after $\mathrm{HI}$ and in $\mathrm{P} 13$ sham-treated rats $(n=4$ per time point). MAP2 staining was scored in $(A)$ the hippocampus and $(B)$ the cortex. A representative example of MAP2 staining at $48 \mathrm{~h}$ after $\mathrm{HI}$ in the ipsilateral $(C)$ and contralateral $(D)$ hippocampus is shown. $* p<0.05 v s$ sham.
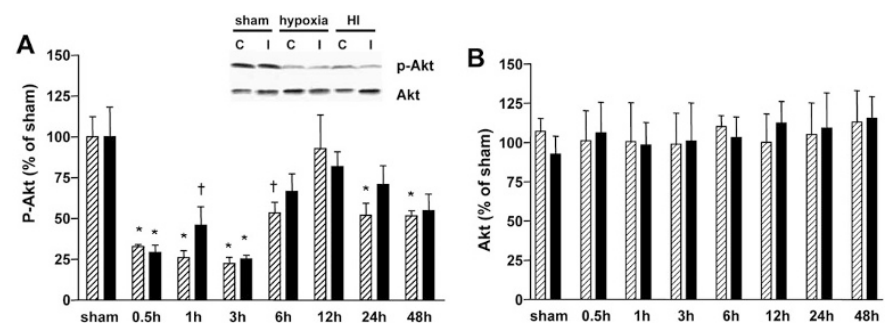

Figure 3. Western blot analysis was performed for P-Akt in homogenates of the ipsi- and contralateral hemisphere from sham-treated rats and rats $0.5,1$, $3,6,12,24$, and $48 \mathrm{~h}$ after $\mathrm{HI}$ ( $n=7$ per time point). P-Akt was normalized for total Akt. Data are presented as percentage of the levels in the sham rats; contralateral (hatched bars), ipsilateral (black bars). The insert depicts a representative Western blot for P-Akt of sham-treated rats and rats $0.5 \mathrm{~h}$ after hypoxia or HI. $* p<0.001, \dagger p<0.05 v s$ sham. There was no significant difference between the ipsi- and contralateral hemisphere at any time point after HI.

0.05). There was no significant difference between the ipsiand contralateral hemisphere at any time point. Levels of total-Akt did not change over time after HI (Fig. 3b). Hypoxia alone resulted in the same changes in P-Akt as observed in both hemispheres of HI-treated rats (see inset, Fig. 3).

$\boldsymbol{P}$-ERK1/2. The level of P-ERK1/2 was significantly $(p<$ 0.001 ) increased in both ipsi- and contralateral hemispheres at $0.5,1$, and $3 \mathrm{~h}$ after HI (Fig. 4) in comparison with shamtreated rats. Moreover, P-ERK1/2 levels were significantly higher in the ipsi- than in the contralateral hemisphere at these time points (Fig. $4 a$ ). Subsequently, at $6 \mathrm{~h}$ post-HI, P-ERK1/2 levels returned to baseline levels. The levels of total ERK did not change over time after HI (Fig. 4b). Hypoxia alone resulted in an increase in P-ERK1/2 levels that was similar to the P-ERK1/2 levels present in the contralateral hemisphere of HI-treated rats (see inset, Fig. 4).

$\boldsymbol{H I F}-1 \boldsymbol{\alpha}$. HI-induced a significant $(p<0.001)$ increase in HIF- $1 \alpha$ protein expression in both the contra- and ipsilateral hemisphere at $3 \mathrm{~h}$ after the event (Fig. 5). HIF-1 $\alpha$ protein

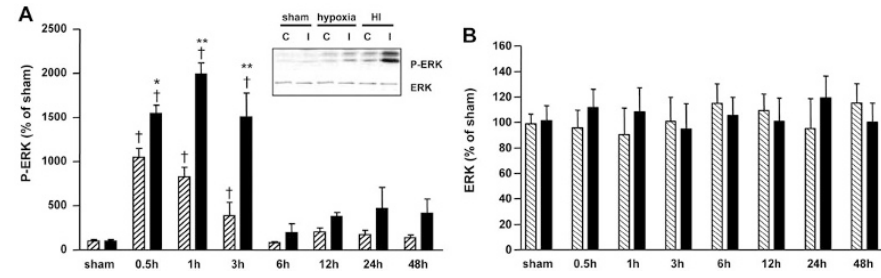

Figure 4. Western blot analysis performed for P-ERK1/2 and total ERK in homogenates of the ipsi- and contralateral hemisphere from sham-treated rats and rats $0.5,1,3,6,12,24$, and $48 \mathrm{~h}$ after $\mathrm{HI}(n=7$ per time point). (A) Expression of P-ERK normalized for total-ERK. B. Total ERK. Contralateral (hatched bars), ipsilateral (black bars). The inset depicts a representative Western blot for P-ERK of sham-treated rats and rats $0.5 \mathrm{~h}$ after hypoxia or HI. $\dagger p<0.001$ vs sham; $* p<0.05$, ** $p<0.01$ vs contralateral.

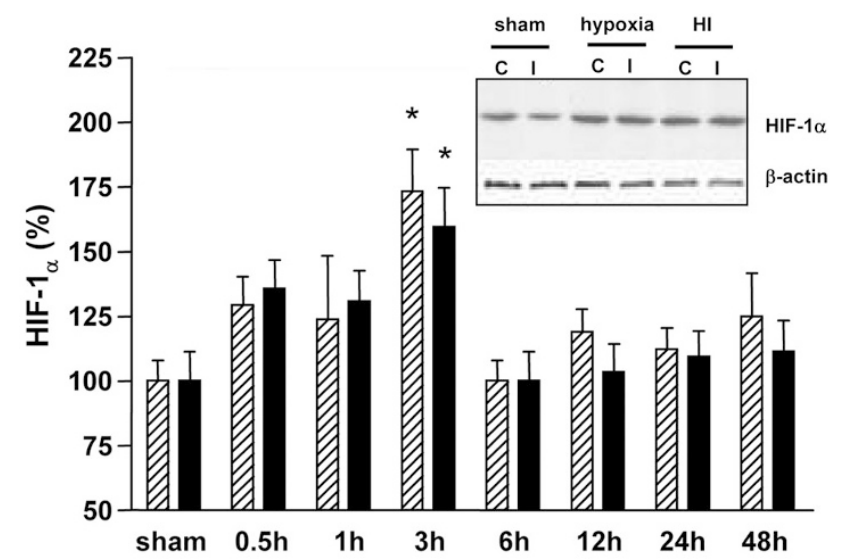

Figure 5. Western blot analysis performed for HIF- $1 \alpha$ in homogenates from sham-treated rats and rats $0.5,1,3,6,12,24$, and $48 \mathrm{~h}$ after $\mathrm{HI}(n=7$ per time point). Data are presented as percentage of the levels in the sham rats; contralateral (hatched bars), ipsilateral (black bars). The inset depicts a representative Western blot for HIF- $1 \alpha$ of the brains of sham-treated rats and rats $0.5 \mathrm{~h}$ after hypoxia or HI. ${ }^{*} p<0.05 v s$ sham. There was no significant difference between the ipsi- and contralateral hemisphere at any time point after HI.

levels returned to levels observed in sham-treated animals at 6 $\mathrm{h}$ after HI. There was no significant difference in HIF- $1 \alpha$ protein expression between the ipsi- and contralateral hemisphere at any time point after HI. Hypoxia alone induced an increase in HIF1- $\alpha$ expression in both hemispheres as well (see inset, Fig. 5).

HSP70. At later time points after HI, from $6 \mathrm{~h}$ onwards, a significant increase in HSP70 expression was observed in the ipsilateral hemisphere only (Fig. 6). The level of HSP70 in the ipsilateral hemisphere continued to increase at 12,24 , and $48 \mathrm{~h}$ post-HI. We did not observe any change in HSP70 expression over time in the contralateral hemisphere of HItreated rats and hypoxia alone did not lead to any change in HSP-70 expression either (see inset, Fig. 6A). These data were confirmed by immunohistochemistry (Fig. 6, B-E). Clear HSP70 staining was observed in cells with neuronal morphology in the ipsilateral hemisphere only. In the contralateral hemisphere, only very few HSP70-positive cells were observed and there was no change over time (Fig. $6 D$ versus $E$ and data not shown).

Cytokines. After HI, mRNA expression for the cytokines TNF- $\alpha$, TNF- $\beta$, and IL- $1 \beta$ was detectable by Rnase protection assay. In brains from sham-treated animals, no mRNA expres- 

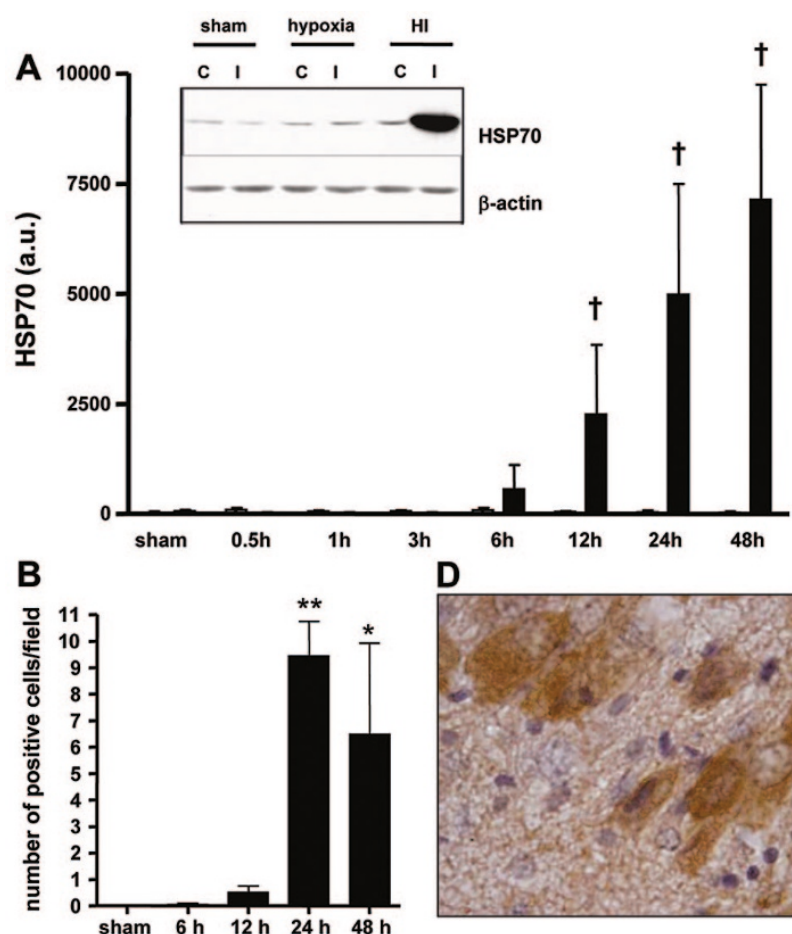

D

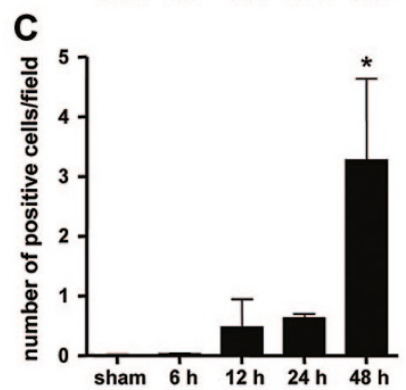

E

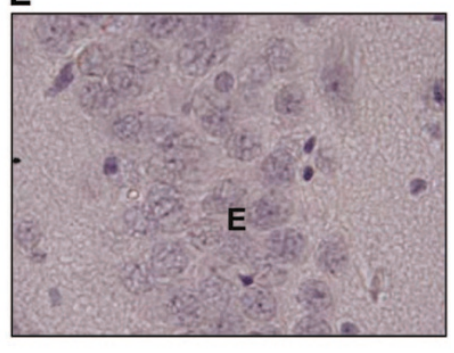

Figure 6. (A) Western blot analysis performed for HSP70 in brain homogenates of the ipsi- and contralateral hemisphere from sham-treated rats and rats $0.5,1,3,6,12,24$, and $48 \mathrm{~h}$ after $\mathrm{HI}(n=7$ per time point). Contralateral (hatched bars), ipsilateral (black bars) The inset depicts a representative Western blot for HSP70 of sham-treated rats and rats $24 \mathrm{~h}$ after hypoxia or HI. $\dagger p<0.05$ vs sham. $(B-E)$ Results of immunohistochemical analysis of HSP70 expression in the ipsilateral hippocampus $(B)$ and cortex $(C)$ of sham-treated rats and rats $6,12,24$, and $48 \mathrm{~h}$ after $\mathrm{HI}(n=4$ per time point, $* p<0.05 * * p<0.01$ vs sham). Example of HSP70 staining in ipsilateral cortex $(D)$ and contralateral cortex $(E)$ at $48 \mathrm{~h}$ after HI.

sion for cytokines could be detected. Expression of TNF- $\alpha$, TNF- $\beta$, and IL- $1 \beta$ was detectable $6 \mathrm{~h}$ after HI, and peaked at $24 \mathrm{~h}$. After $48 \mathrm{~h}$, mRNA expression for the cytokines had returned to the levels at $6 \mathrm{~h}$ (Fig. 7, $a-c$ ). There was a large individual variation in the cytokine levels after HI. However, there was no significant difference between expression of the cytokines in ipsi- and contralateral hemispheres. The data for IL- $1 \beta$ were confirmed by real-time PCR analysis (Fig. $7 d$ ). Hypoxia alone induced an increase in IL- $1 \beta$ mRNA expression in both hemispheres as well (Fig. $7 d$ ).

To investigate whether the appearance of cytokine expression is associated with the presence of macrophages/activated microglia in the brain, we performed immunohistochemical staining for CD68. As expected, the number of macrophages/ activated microglia in the ipsilateral hemisphere is increased,
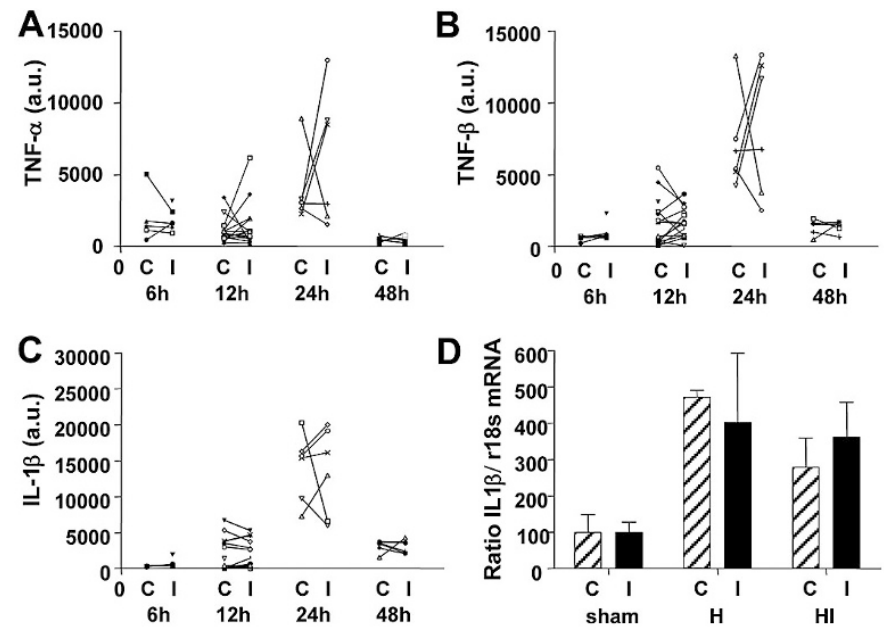

Figure 7. Levels of mRNA of several cytokines in homogenates of the ipsiand contralateral hemisphere from rats at $6(n=6), 12(n=12), 24(n=6)$, and $48(n=6) \mathrm{h}$ after $\mathrm{HI}$ and from P13 sham-treated rats $(n=6)$. In homogenates of the brain from sham-treated animals, no mRNA expression for cytokines could be detected. After HI, expression of mRNA for the cytokines (a) TNF- $\alpha$, (b) TNF- $\beta$, and (c) IL- $\beta \beta$ was detectable. (d) IL-1 mRNA of sham-treated rats and rats $24 \mathrm{~h}$ after hypoxia or hypoxia-ischemia. There was no significant difference between the ipsi- and contralateral hemisphere at any time point after HI.

starting at $12 \mathrm{~h}$ until $48 \mathrm{~h}$ after HI (Fig. 8, $a$ and $b$ ). We did not detect a change in the number of CD68-positive cells in the contralateral hemisphere (Fig. 8, $c$ and $d$, and data not shown). Collectively, these data suggest that activation of microglia to the stage of CD68 expression and/or macrophage influx is not necessary for increased cytokine mRNA expression in the contralateral hemisphere.
A

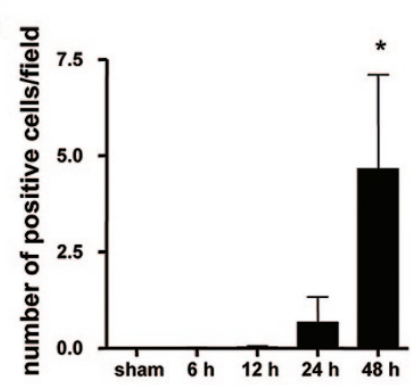

B

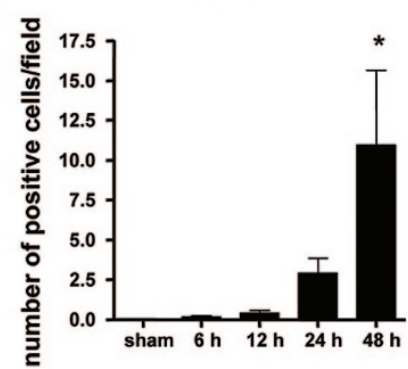

C

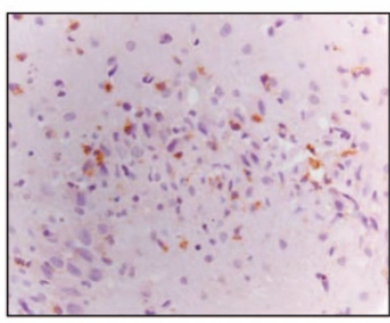

D

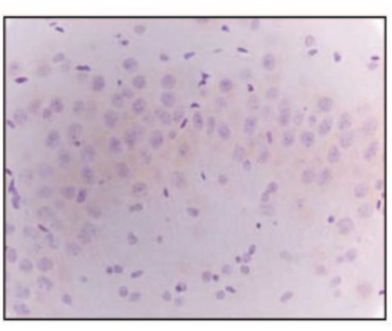

Figure 8. Immunohistochemistry for CD68 was performed 6, 12, 24, and $48 \mathrm{~h}$ after $\mathrm{HI}$ and in P13 sham-treated rats $(n=4$ per time point). An increment in CD68 expression reflects an increase in activated macrophages/ glial cells. The number of positive cells per high power field was determined in $(A)$ the ipsilateral hippocampus and $(B)$ the ipsilateral cortex. A representative example of CD68 staining at $48 \mathrm{~h}$ after $\mathrm{HI}$ in the ipsilateral $(C)$ and contralateral $(D)$ CA3 is shown. ${ }^{*} p<0.05$ vs sham. 


\section{DISCUSSION}

To our knowledge, this is the first paper describing the detailed kinetics of ipsi-and contralateral early changes in expression of multiple mediators after exposure of neonatal P12 rats to cerebral HI using the Vannucci-Rice model. The most important observation in this study is that most of the molecular changes detected in the ipsilateral hemisphere after $\mathrm{HI}$ also occur in the contralateral hemisphere. These findings are surprising because our data confirm that this model of $\mathrm{HI}$ induces long-term brain damage exclusively in the ipsilateral hemisphere. At $6 \mathrm{wk}$ after $\mathrm{HI}$, there were no significant differences in histologic damage between the contralateral side of the HI-treated animals and both hemispheres of shamoperated control animals, confirming that no neuronal damage occurs in the contralateral hemisphere. Moreover, early after HI (at 6-48 h after HI) we only detected loss of MAP2 staining in the ipsilateral hemisphere, indicating that neuronal integrity is only lost in the ipsilateral hemisphere. In accordance with the neuronal damage in the ipsilateral hemisphere only, we observed increased expression of HSP70 only in the ipsilateral hemisphere and with kinetics similar to loss of MAP2 expression. Most studies describe increased expression of HSP70 as a protective mechanism, because binding of the chaperone HSP70 to cellular proteins is thought to reduce degradation of proteins (14). However, it has also been shown that overexpression of HSP70 can promote TNF- $\alpha$-mediated neuronal cell apoptosis by inhibiting nuclear factor $(\mathrm{NF}) \kappa \mathrm{B}$ activation. In addition, in adult mice overexpressing HSP70, neuronal damage is more pronounced after common carotid artery occlusion than in wild-type mice (22). The increase in HIF- $1 \alpha$ was detectable in both the ipsi- and contralateral hemisphere and also after hypoxia only. These findings are not surprising inasmuch as hypoxia is the crucial signal for increased expression of HIF-1 $\alpha(23,24)$. Simultaneously with increased HIF- $1 \alpha$ protein expression, we observed a sharp decrease in P-Akt. These data seem to be in contradiction with data in the literature, inasmuch as an early increase in P-Akt has been described after in vitro exposure of neuronal cells to hypoxia (25) in an adult murine stroke model (26). These increases in P-Akt have been implicated in down-regulation of apoptosis through inhibition of pro-apoptotic mediators such as Bad, FasLigand, and caspases-9 and -3 as well as cytochrome-c release, indicating that increases in P-Akt after hypoxic-ischemic events may be protective $(27,28)$. In our model of neonatal cerebral HI in P12 rats, we observed, however, a biphasic decline in P-Akt rather than an increase, suggesting that the change in P-Akt in neonatal animals will not contribute to neuroprotection. Moreover, because we detected bilateral decreases in P-Akt, the decrease in P-Akt is not sufficient for the induction of neuronal damage in the ipsilateral hemisphere either.

The more pronounced increase in expression of P-ERK1/2 in the ipsilateral hemisphere compared with the contralateral hemisphere, suggests that increased P-ERK1/2 may contribute to damage. Indeed, inhibition of phosphorylation of ERK after HI has been shown to be neuroprotective $(29,30)$. Moreover, Wang et al. (31) have described that, after neonatal HI,
ERK1/2 activation occurred primarily in those cerebral neurons that showed signs of cell damage. It should be noted, however, that we did observe a more modest increase in P-ERK1/2 in the contralateral hemisphere and in the brain of animals exposed to hypoxia only as well.

To gain more insight in the inflammatory response after HI, we determined cytokine mRNA expression and show that IL- $1 \beta$, TNF- $\beta$, and TNF- $\alpha$ expression is increased after HI. Again, the cytokines increased in both the ipsi- and contralateral hemisphere to the same extent and exposure of P12 rats to hypoxia alone induces a similar increase in the expression of the pro-inflammatory cytokine IL- $1 \beta$. Moreover, we have data to suggest that also the activation of the transcription factor $\mathrm{NF} \kappa \mathrm{B}$ occurs in both the ipsi- and contralateral hemisphere to the same extent (van den Tweel et al., in press). However, there are also data in the literature suggesting that neonatal cerebral $\mathrm{HI}$ induces an increase in the expression of proinflammatory cytokines in the ipsilateral hemisphere only (17). The major difference with our study is that we used P12 rats whereas this earlier study was performed in P7 rats.

In conclusion, we have observed that exposure of the neonatal P12 rat brain to $\mathrm{HI}$ induces rapid and transient bi-lateral changes in HIF-1 $\alpha$, P-Akt, P-ERK1/2, and proinflammatory cytokine expression in conjunction with unilateral increases in HSP70 and unilateral neuronal damage. Moreover, hypoxia alone resulted in similar changes in HIF- $1 \alpha$, IL- $\beta$, and P-Akt, a smaller increase in p-ERK1/2, but no HSP70 expression or neuronal damage, which matches the pattern observed in the contralateral hemisphere. The results of our study lead to the question whether the changes in regulatory molecules that occur in both hemispheres after $\mathrm{HI}$, are of any importance for the observed damage. Intervention studies have clearly shown that inhibition of mediators that are increased in both hemispheres can still prevent damage. For example, treatment with IL-1RA can reduce neuronal damage in models of HI (32-34). In this respect, it is interesting that an increased level of IL-1 $\beta$ in itself is not toxic for healthy neurons in adult rats, whereas IL-1RA protects against brain damage in multiple models $(33,34)$. The question remains how death-signaling pathways function in the ipsilateral hemisphere. Are neurons "sensitized" by the ischemic event due to e.g. a lack of glucose, which leads to cell death if followed by alterations in hypoxia-induced molecular mediators? It should be noted that in the model we used, ischemia alone or hypoxia alone are not enough to cause cerebral damage (9). Therefore, we suggest that most of the changes we observed in both hemispheres are not neurotoxic or neuroprotective by themselves but need additional signals provided by the ischemic milieu in the ipsilateral hemisphere to contribute to cell death. It still remains a challenge, however, to identify the actual signal(s) in the ipsilateral hemisphere that results in neuronal death.

Acknowledgments. The authors thank Maaike Yedema, Edina Tjepkema, and Mirjam Maas for their excellent technical assistance. 


\section{REFERENCES}

1. Cowan F, Rutherford M, Groenendaal F, Eken P, Mercuri E, Bydder GM, Meiners LC, Dubowitz LM, de Vries LS 2003 Origin and timing of brain lesions in term infants with neonatal encephalopathy. Lancet 361:736-742

2. Peeters C, van Bel F 2001 Pharmacotherapeutical reduction of post-hypoxicischemic brain injury in the newborn. Biol Neonate 79:274-280

3. Fellman V, Raivio KO 1997 Reperfusion injury as the mechanism of brain damage after perinatal asphyxia. Pediatr Res 41:599-606

4. Rice JE 3rd, Vannucci RC, Brierley JB 1981 The influence of immaturity on hypoxic-ischemic brain damage in the rat. Ann Neurol 9:131-141

5. Wang X, Zhu C, Qiu L, Hagberg H, Sandberg M, Blomgren K 2003 Activation of ERK1/2 after neonatal rat cerebral hypoxia-ischaemia. J Neurochem 86:351-362

6. Zhang SX, Gozal D, Sachleben LR Jr., Rane M, Klein JB, Gozal E 2003 Hypoxia induces an autocrine-paracrine survival pathway via platelet-derived growth factor (PDGF)-B/PDGF-beta receptor/phosphatidylinositol 3-kinase/Akt signaling in RN46A neuronal cells. FASEB J 17:1709-1711

7. Shibata M, Yamawaki T, Sasaki T, Hattori H, Hamada J, Fukuuchi Y, Okano H, Miura M 2002 Upregulation of Akt phosphorylation at the early stage of middle cerebral artery occlusion in mice. Brain Res 942:1-10

8. Mottet D, Dumont V, Deccache Y, Demazy C, Ninane N, Raes M, Michiels C 2003 Regulation of hypoxia-inducible factor-1alpha protein level during hypoxic conditions by the phosphatidylinositol 3-kinase/Akt/glycogen synthase kinase 3beta pathway in HepG2 cells. J Biol Chem 278:31277-31285

9. Gao N, Ding M, Zheng JZ, Zhang Z, Leonard SS, Liu KJ, Shi X, Jiang BH 2002 Vanadate-induced expression of hypoxia-inducible factor 1 alpha and vascular endothelial growth factor through phosphatidylinositol 3-kinase/Akt pathway and reactive oxygen species. J Biol Chem 277:31963-31971

10. Minet E, Arnould T, Michel G, Roland I, Mottet D, Raes M, Remacle J, Michiels C 2000 ERK activation upon hypoxia: involvement in HIF-1 activation. FEBS Lett 468:53-58

11. Semenza G 2002 Signal transduction to hypoxia-inducible factor 1. Biochem Pharmacol 64:993-998

12. Semenza GL, Roth PH, Fang HM, Wang GL 1994 Transcriptional regulation of genes encoding glycolytic enzymes by hypoxia-inducible factor 1 . J Biol Chem 269:23757-23763

13. Vreugdenhil HA, Haitsma JJ, Jansen KJ, Zijlstra J, Plotz FB, Van Dijk JE, Lachmann B, Van Vught H, Heijnen CJ 2003 Ventilator-induced heat shock protein 70 and cytokine mRNA expression in a model of lipopolysaccharide-induced lung inflammation. Intensive Care Med 29:915-922

14. Garrido C, Gurbuxani S, Ravagnan L, Kroemer G 2001 Heat shock proteins: endogenous modulators of apoptotic cell death. Biochem Biophys Res Commun 286:433-442

15. Asea A, Rehli M, Kabingu E, Boch JA, Bare O, Auron PE, Stevenson MA, Calderwood SK 2002 Novel signal transduction pathway utilized by extracellular HSP70: role of toll-like receptor (TLR) 2 and TLR4. J Biol Chem 277:15028-15034

16. Vabulas RM, Ahmad-Nejad P, Ghose S, Kirschning CJ, Issels RD, Wagner H 2002 HSP70 as endogenous stimulus of the Toll/interleukin-1 receptor signal pathway. J Biol Chem 277:15107-15112

17. Bona E, Andersson AL, Blomgren K, Gilland E, Puka-Sundvall M, Gustafson K, Hagberg H 1999 Chemokine and inflammatory cell response to hypoxia-ischemia in immature rats. Pediatr Res 45:500-509
18. Dobbing J, Sands J 1979 Comparative aspects of the brain growth spurt. Early Hum Dev 3:79-83

19. Romijn HJ, Hofman MA, Gramsbergen A 1991 At what age is the developing cerebral cortex of the rat comparable to that of the full-term newborn human baby? Early Hum Dev 26:61-67

20. Hagberg H, Ichord R, Palmer C, Yager JY, Vannucci SJ 2002 Animal models of developmental brain injury: relevance to human disease. A summary of the panel discussion from the Third Hershey Conference on Developmental Cerebral Blood Flow and Metabolism. Dev Neurosci 24:364-366

21. Gilland E, Bona E, Hagberg H 1998 Temporal changes of regional glucose use, blood flow, and microtubule-associated protein 2 immunostaining after hypoxiaischemia in the immature rat brain. J Cereb Blood Flow Metab 18:222-228

22. Olsson T, Hansson O, Nylandsted J, Jaattela M, Smith ML, Wieloch T 2003 Lack of neuroprotection by heat shock protein 70 overexpression in a mouse model of global cerebral ischemia. Exp Brain Res 154:442-449

23. Bergeron M, Gidday JM, Yu AY, Semenza GL, Ferriero DM, Sharp FR 2000 Role of hypoxia-inducible factor-1 in hypoxia-induced ischemic tolerance in neonatal rat brain. Ann Neurol 48:285-296

24. Wang X, Deng J, Boyle DW, Zhong J, Lee WH 2004 Potential Role of IGF-I in hypoxia tolerance using a rat hypoxic-ischemic model: activation of hypoxiainducible factor $1 \alpha$. Pediatr Res 55:385-394

25. Zhang SX, Gozal D, Sachleben LR Jr., Rane M, Klein JB, Gozal E 2003 Hypoxia induces an autocrine-paracrine survival pathway via platelet-derived growth factor (PDGF)-B/PDGF-beta receptor/phosphatidylinositol 3-kinase/Akt signaling in RN46A neuronal cells. FASEB J 17:1709-1711

26. Shibata M, Yamawaki T, Sasaki T, Hattori H, Hamada J, Fukuuchi Y, Okano H, Miura M 2002 Upregulation of Akt phosphorylation at the early stage of middle cerebral artery occlusion in mice. Brain Res 942:1-10

27. Guan J, Bennet L, Gluckman PD, Gunn AJ 2003 Insulin-like growth factor-1 and post-ischemic brain injury. Prog Neurobiol 70:443-462

28. Kermer P, Klocker N, Labes M, Bahr M 2000 Insulin-like growth factor-I protects axotomized rat retinal ganglion cells from secondary death via PI3-K-dependent Akt phosphorylation and inhibition of caspase-3 in vivo. J Neurosci 20:2-8

29. Namura S, Iihara K, Takami S, Nagata I, Kikuchi H, Matsushita K, Moskowitz MA, Bonventre JV, Alessandrini A 2001 Intravenous administration of MEK inhibito U0126 affords brain protection against forebrain ischemia and focal cerebral ischemia. Proc Natl Acad Sci U S A 98:11569-11574

30. Alessandrini A, Namura S, Moskowitz MA, Bonventre JV 1999 MEK1 protein kinase inhibition protects against damage resulting from focal cerebral ischemia Proc Natl Acad Sci U S A 96:12866-12869

31. Wang X, Zhu C, Qiu L, Hagberg H, Sandberg M, Blomgren K 2003 Activation of ERK1/2 after neonatal rat cerebral hypoxia-ischaemia. J Neurochem 86:351362

32. Hagberg H, Gilland E, Bona E, Hanson LA, Hahin-Zoric M, Blennow M, Holst M, McRae A, Soder O 1996 Enhanced expression of interleukin (IL)-1 and IL-6 messenger RNA and bioactive protein after hypoxia-ischemia in neonatal rats. Pediatr Res 40:603-609

33. Loddick SA, Rothwell NJ 1996 Neuroprotective effects of human recombinan interleukin-1 receptor antagonist in focal cerebral ischaemia in the rat. J Cereb Blood Flow Metab 16:932-940

34. Rothwell N, Allan S, Toulmond S 1997 The role of interleukin 1 in acute neurodegeneration and stroke: pathophysiological and therapeutic implications. J Clin Invest 100:2648-2652 